\title{
Laparoscopic Complete Mesocolic Excision for Double Flexural Colon Cancers
}

\author{
Takeru Matsuda, $\mathrm{MD}, \mathrm{PhD}^{1,2}$, Hiroshi Hasegawa, $\mathrm{MD}, \mathrm{PhD}^{2}$, Kimihiro Yamashita, $\mathrm{MD}, \mathrm{PhD}^{2}$, \\ Nobuhisa Takase, $\mathrm{MD}, \mathrm{PhD}^{2}$, Gousuke Takiguchi, $\mathbf{M D}, \mathbf{P h D}^{2}$, Masashi Yamamoto, $\mathbf{M D}, \mathbf{P h D}^{2}$, \\ Shingo Kanaji, MD, $\mathrm{PhD}^{2}$, Taro Oshikiri, $\mathrm{MD}, \mathrm{PhD}^{2}$, Tetsu Nakamura, $\mathrm{MD}, \mathrm{PhD}^{2}$, Satoshi Suzuki, $\mathrm{MD}, \mathrm{PhD}^{2}$, and \\ Yoshihiro Kakeji, MD, PhD $^{2}$
}

${ }^{1}$ Division of Minimally Invasive Surgery, Department of Surgery, Kobe University Graduate School of Medicine, Kobe, Japan; ${ }^{2}$ Division of Gastrointestinal Surgery, Department of Surgery, Kobe University Graduate School of Medicine, Kobe, Japan

\begin{abstract}
Background. Laparoscopic complete mesocolic excision (CME) for hepatic or splenic flexural colon cancer is considered technically demanding. The double (hepatic and splenic) flexural colon cancers are rare, and the laparoscopic CME procedure for such disease is not standardized. Methods. This video presents laparoscopic CME for double (hepatic and splenic) flexural colon cancers using a medial and cranial approach.

Results. The patient was a 60 -year-old woman with the diagnosis of splenic flexure cancer (cT4N1M0) and hepatic flexure cancer (cT3NOM0). Laparoscopic subtotal colectomy was performed. First, the left colic artery was divided at its origin, and the inferior mesenteric vein also was divided at the same level. The descending mesocolon was widely separated from the retroperitoneal tissues using a
\end{abstract}

medial approach. Then, lymph node dissection along the surgical trunk was performed using a cranial approach. Finally, the transverse mesocolon was divided at the inferior border of the pancreas, and CME was achieved. The specimen was extracted through a small incision at the umbilicus, and side-to-side ileo-sigmoid anastomosis was performed extracorporeally.

Conclusions. The approach presented in the video might be useful for standardization of laparoscopic CME for double flexural colon cancers.

Publisher's Note Springer Nature remains neutral with regard to jurisdictional claims in published maps and institutional affiliations.
Electronic supplementary material The online version of this article (https://doi.org/10.1245/s10434-019-07329-4) contains supplementary material, which is available to authorized users.
(C) Society of Surgical Oncology 2019

First Received: 3 November 2018;

Published Online: 29 March 2019

T. Matsuda, MD, PhD

e-mail: takerumatsuda@nifty.com 